\title{
COMUNICAÇÃO \\ A filosofia da história universal de Friedrich Schiller: uma introdução
}

\section{COMMUNICATION}

Friedrich Schiller's philosophy of universal history: an introduction

\section{Pedro Spinola Pereira Caldas*}

Não é fácil a tarefa de apresentar um texto de Friedrich Schiller, que, apesar de importante para a filosofia da história, esse campo representa apenas uma centelha de sua obra. O leitor, sobretudo aquele que tem contato pela primeira vez com Schiller, nesse texto sobre a história universal, jamais pode perder de vista que seu autor não era um filósofo da história, muito embora a história seja um tema constante em seu percurso intelectual. Schiller foi um grande dramaturgo e um filósofo decisivo para os estudiosos de estética. Sua obra, portanto, é irredutível às atuais exigências de especialização e atomização do conhecimento.

Todavia, só temos a perder se colocarmos Schiller sobre um pedestal inatingível, mesmo porque seu pensamento e sua época não permitem uma visão tão uniforme e tão simples. Muito mais interessante é perceber como ainda nos provoca um autor cuja vida, iniciada em 10 de novembro de 1759 em Marbach, foi caracterizada por um trabalho desgastante (ALT, 2004, p. 6-7) ${ }^{1}$ e pela tensão.

Nas palavras de um estudioso de sua obra, para conhecermos um pouco melhor Schiller, é necessário perceber que:

\begin{abstract}
Schiller só pode ser compreendido como um contemporâneo de nossa época quando se tornarem claros os seus conflitos com sua própria época. Um Schiller que seja representante e crítico do Iluminismo bem pode ser nosso contemporâneo, porque nós, representantes autocríticos de uma modernidade pós-moderna, estamos no fim de um processo cujo início ele acompanhou criticamente (HOFMANN, 2004, p. 194).
\end{abstract}

\footnotetext{
* Doutor em História Social da Cultura pela Pontifícia Universidade Católica do Rio de Janeiro (PUCRio). Professor Associado do Departamento de História da Universidade Federal do Estado do Rio de Janeiro (UNIRIO). Pesquisador do CNPq.

Recebido em outubro de 2017 | Aprovado em fevereiro de 2018.

${ }^{1}$ Chega a ser sintomático como Schiller emprega frequentemente a palavra "Fleiss" (esforço, dedicação) no texto traduzido para esta coletânea. Sugiro a leitura de "Hora difícil", um belo conto de Thomas Mann, no qual um Schiller atormentado não consegue separar dor e criação artística. É uma imagem muito próxima a de Gustav von Aschenbach, de Morte em Veneza (MANN, 2000).
} 
Portanto, valerá a pena tentar, sem esquecer a complexidade de sua obra, expor seu impasse, que é evidente neste dualismo constante entre "entusiasmo e ceticismo, entre idealismo e desilusão", para empregar a caracterização de Schiller feita por Michael Hofmann (2003, p. 31), e identificá-lo em sua concepção de história.

Esse impasse já é sensível em seus anos de formação. Com apenas treze, deixa a família para estudar em uma rigorosa escola militar, comandada pelo Duque Carl Eugen. Seus sete anos de estudos - incluído aí, sobretudo, de Medicina - deram a Schiller uma formação sólida que lhe possibilitou contato com o empirismo britânico, com o materialismo francês e com a filosofia de Leibniz e Wolff. Schiller formou-se em meio ao absolutismo esclarecido, em que a estrita vigilância do comportamento não impedia o conhecimento com teorias vinculadas ao iluminismo. Mas a disciplina era, de fato, asfixiante: Schiller publicaria, anonimamente, a sua primeira peça - Os Bandoleiros [Die Räuber] - em 1781, e, para assistir à estreia da mesma em janeiro de 1782, no Teatro Nacional de Mannheim, sairia de Stuttgart sem a autorização do duque. A descoberta da "fuga" lhe valeria uma proibição para escrever. Foi o que bastou para Schiller deixar às escondidas a cidade onde vivia sob a ambígua proteção militar (HOFMANN, 2003, p. 15-17; ALT, 2004, p. 11-12).

Mas a aposta na liberdade teve um custo. O poeta viveria nos anos seguintes sob condições materiais constrangedoras, trabalhando como dramaturgo em Meiningen onde escreveu Intriga e Amor - e em Mannheim; quatro admiradores salvaram-no da miséria que, sem jamais tê-lo visto, decidiram dar-lhe apoio financeiro, e, mais do que isso, a amizade. Os anos seguintes seriam passados em Leipzig e Dresden, cujos fortes laços lhe inspirariam a compor o poema Ode à alegria [An die Freude], que se tornaria conhecido como a letra do coral do famosíssimo quinto movimento da $9^{\mathrm{a}}$. Sinfonia de Beethoven (HOFMANN, 2003, p. 18).

De acordo com Hofmann (2003, p. 19-20), em 1787, quando se torna inviável manter-se financeiramente com a ajuda de amigos, Schiller deixa a Saxônia (onde Dresden e Leipzig situam-se) e se muda para Weimar, onde viviam intelectuais consagrados como Goethe, Herder e Wieland. Sua principal motivação para mudar-se novamente e passar a viver na pequena cidade da Turíngia era, justamente, conhecer Goethe, àquela altura já um "monumento nacional". Com a ajuda de Wieland, consegue se manter e publicar sua primeira obra historiográfica: História da Queda da União Holandesa perante o governo espanhol [Geschichte der Abfall der vereinigten Niederlande vor dem spanischen Regierung]. Mas uma grande ajuda também vem de 
Goethe, que lhe consegue uma indicação para o cargo de professor de História na Universidade de Jena, em 1789. Sua primeira atividade como professor foi justamente proferir a conferência que deu origem ao texto aqui traduzido.

Uma séria doença pulmonar, iniciada em 1791 e da qual jamais se curaria até a sua morte em 9 de maio de 1805, encerra sua carreira como professor universitário, e, com ela, sua dedicação à historiografia. Dá-se início a uma nova fase, marcada pelos estudos filosóficos sobre estética e pela amizade com Goethe, que lhe serviria de incentivo para retomar suas atividades poéticas e literárias. Novamente, ele contaria com a ajuda de admiradores. Um deles foi o crítico dinamarquês Jens Baggesen, protegido do príncipe de Augustenburg, que toma conhecimento do estado de saúde de Schiller e viabilizou apoio financeiro ao poeta. Schiller passaria a ter condições mínimas para, a partir de uma troca de cartas, aprofundar-se em seus estudos filosóficos, que, depois, resultariam em textos importantes, sobretudo, seus dois ensaios Educação estética da humanidade e Poesia ingênua e sentimental, ambos publicados entre 1795 e 1796 (BARBOSA, 2004), e, também, na editoração do importante periódico As Horas. Nos últimos anos de sua vida, tornaria a se dedicar ao teatro, escrevendo algumas peças importantes para a história das artes cênicas, tais como a monumental trilogia Wallenstein (1798/1799), Maria Stuart (1800), Noiva de Messina (1803) e Guilherme Tell (1804).

\section{A ideia de história na obra de Schiller}

Além do texto sobre a história universal, a ideia de história na obra de Friedrich Schiller pode ser vista sob vários ângulos: pelas suas peças históricas, pela sua obra historiográfica, pelos seus ensaios filosóficos (nos quais se pode trabalhar a relação do moderno com a antiguidade), e mesmo pelo seu conceito do sublime (VIEIRA, 2009), cuja importância para a teoria da história já foi destacada por autores como Frank Ankersmit. Todavia, o mais interessante é o que nos diz Johannes Süssmann: “deve ser lembrado (...) que Schiller era um trágico (...) Cada figura, cada ação, cada ideia (...) encontra sempre seu oposto, isto é, ela é sempre relativizada". (SÜSSMANN, 2006, p. 47). Essa me parece ser uma chave bem interessante de leitura, sendo apenas um prisma possível dentre vários capazes de abordar uma obra tão complexa. 
A concepção trágica ${ }^{2}$ explica parte do impacto de Os Bandoleiros, que, entre outras razões, se deve justamente à exposição de um impasse, no qual o passado aparece gasto e desbotado na figura do "velho" Moor.

Não sei se seria exagero afirmar o quanto Schiller foi influenciado por Shakespeare nessa peça. Personagem quase idêntico a Rei Lear, Moor é pai de dois filhos que, cada qual à sua maneira, o abandonam, ao buscar seus próprios caminhos. Um deles (Franz) é ambicioso, ardiloso e calculista como um Ricardo III, mas, se deixarmos de lado os juízos moralistas, veremos que ele representa toda tentativa de controlar o futuro, de se assegurar do processo histórico: "quero exterminar tudo aquilo que está à minha volta! Tudo aquilo que me impede de vir a ser Senhor (...) Que eu me permita fazer uso da violência só reflete a falta de amor de que fui vítima" (SCHILLER, 2001, p. 27 - Ato I, Cena 1). Franz Moor julga-se preterido em favor de seu irmão, Karl Moor, contra quem conspira para vir a herdar todo o poder do pai. Karl Moor lidera um grupo de salteadores (daí o título da peça), capazes de aterrorizar, ainda que em nome da liberdade pura e simples. Suas ações não visam a obtenção de um determinado fim (o poder, como é o caso de Franz). O horror de Franz Moor é pelas leis, pelas "normas abstratas" que cerceiam a ação criativa do ser humano. Ele rejeita veementemente "um punhado de ducados piolhentos", e afirma, o contrário: "Será que sou obrigado a deixar meu corpo sofrer dentro de um espartilho apertado e ajustar minhas vontades ao colete da lei? A lei deteriorou em passos de lesma aquilo que deveria ser o voo da águia. A lei não deu ao mundo nenhum homem de grandeza (...)" (SCHILLER, 2001, p. 31 - Ato I, Cena 2).

Em uma inteligente interpretação da peça, Michael Hofmann (2003, p. 36-48) vê um autêntico impasse trágico nos irmãos Franz e Karl. Ambos representam, em sua tentativa de se afastar de um passado já desprovido de sua função de exemplaridade e de seu brilho, a verdadeira aporia moderna entre o racionalismo abstrato, frio, normativo (Franz) e a espontaneidade individual e criadora (Karl). É nestas horas que se torna difícil discordar de Dilthey, pois Schiller efetivamente cria símbolos capazes de expressar a contradição, ao invés de simplesmente resolvê-la, encobri-la, reduzi-la. É toda a tendência de uma época que se apresentava no palco do Teatro Nacional de Mannheim: "O ser humano busca liberdade e autodeterminação; mas suas ações

\footnotetext{
${ }^{2}$ Para um aprofundamento do conceito de trágico em Schiller, ver Schiller (2011), Do sublime ao trágico, e também Schiller (2004), "Sobre o uso do coro na tragédia", em A noiva de Messina.
} 
desaguam cada vez mais na dependência e na perda da liberdade”. (HOFMANN, 2003, p. 29).

Uma exposição dos impasses da ação humana se fará sentir ao longo de sua obra. Em uma de suas cartas ao Príncipe von Augustenburg, datada de 13 de julho de 1793, Schiller lamenta o destino dos franceses e dos europeus após a execução de Luís XVI:

\begin{abstract}
A tentativa do povo francês de estabelecer-se em seus sagrados direitos humanos e conquistar uma liberdade política trouxe a lume apenas a incapacidade e a indignidade do mesmo, e lançou de volta à barbárie e à servidão não apenas este povo infeliz, mas com ele, também, uma considerável parte da Europa, e um século inteiro (SCHILLER, 2009, p. 74).
\end{abstract}

Todavia, como já foi observado, “(...) nunca é demais lembrar que a sua crítica não é a de um conservador, mas de um homem e cidadão do mundo que não teme levar a própria revolução ao tribunal da razão". (BARBOSA, 2004, p. 22). Schiller lamenta, sem aderir ao simples reacionarismo nostálgico, que a ação revolucionária apaixonada tenha trazido mais destruição do que criação.

Ao insistir na primazia do conflito, Schiller entende a modernidade com precisão, pois a pensa em e partir de suas contradições. Isso também aparece na sua maneira de compreender o moderno em relação à antiguidade clássica. No final da década de 1980, Schiller passa a se dedicar plenamente ao mundo clássico (a ponto de decidir não ler nenhum autor moderno por dois anos) $)^{3}$ (SÜSSEKIND, 2005, p. 245), e um dos frutos desse interesse foi o poema Os Deuses da Grécia (1788), que levou um autor do porte de Jacob Burckhardt (2005, p. 350) a considerá-lo apenas uma idealização da cultura clássica, tomada, então, como exemplo e norma eterna.

Talvez Burckhardt exagere um pouco. O poema é um “(...) lamento pelos deuses que desapareceram" (SÜSSEKIND, 2005, p. 244), mas essa lamúria é conscientemente moderna, como ficará claro posteriormente em seu ensaio Poesia ingênua e sentimental. Nele, não há o favorecimento do antigo sobre o moderno - ou o contrário. A espontaneidade, a unidade consigo mesmo, elemento determinante da natureza que caracteriza o antigo, caracteriza o ingênuo (SCHILLER, 1991, p. 43). É como diz Pedro Süssekind (2005, p. 253): “o ingênuo só se revela como ingênuo aos olhos do homem

\footnotetext{
${ }^{3}$ Consultar Pedro Süssekind (2005), "Schiller e os gregos". Trata-se de um breve e instrutivo estudo sobre a relação de Schiller com a cultura grega.
} 
moderno, isto é, pela ótica do sentimental, que, justamente por sua condição artificial, se interessa pela natureza e ama a ideia exposta por objetos e ações naturais".

É bem verdade que também em outro importante ensaio, as cartas sobre a Educação Estética da Humanidade, o leitor inclina-se a pensar que, para Schiller, há de fato uma superioridade dos antigos perante os modernos, pois esses, governados pelo entendimento analítico, tudo separam, enquanto aqueles, naturais, tudo unem (SCHILLER, 1990, p. 40). Entretanto, esse amor, manifestado na busca por uma harmonia perdida, esse lamento pelos deuses perdidos, está de mãos dadas com a liberdade. Se na natureza tudo é determinado, pois "existe segundo leis próprias e imutáveis" (SCHILLER, 1991, p. 43), há um constrangimento nessa felicidade; ao passo que o moderno, por sua vez, se perde a felicidade da natureza, porém ganha a “(...) condição para a liberdade na cultura." (SCHILLER, 1991, p. 255).

\section{A conferência sobre a história universal: ontem e hoje}

Como seria recebida, hoje, a conferência de Schiller sobre história universal? Certamente, as reações céticas seriam acompanhadas por críticas ao eurocentrismo e ingenuidade do poeta ainda preso na crença em um sentido teleológico de história. Por esse motivo, tem razão Jörn Rüsen ao dizer que a ideia de Schiller sobre história representa um tipo de pensamento que “(...) se apresenta (...) no começo de um desenvolvimento que acreditamos hoje ter chegado ao seu fim” (RÜSEN, 2006, p.15), e, portanto, sua conferência sobre história universal corre o risco de ser apenas um documento significativo de uma época, mas sem a capacidade de provocação.

Será, portanto, um texto meramente documental, signo de uma época, ou ele ainda será capaz de animar debates e de oferecer respostas? ${ }^{4}$ As ambivalências de sua obra estão presentes em suas considerações sobre filosofia da história? Não é o caso de apresentar aqui uma solução, algo que o leitor, caso considere a questão relevante, poderá fazer por si mesmo.

O mais importante é, em primeiro lugar, reconstruir, ainda que insuficientemente, o contexto histórico em que está inserido. Para ficarmos no âmbito alemão, a conferência de Schiller tem, atrás de si, dois textos seminais para a filosofia

\footnotetext{
${ }^{4}$ Jörn Rüsen, sem deixar de ressaltar o quão obsoletas se tornaram algumas posições de Schiller (como a concepção teleológica e eurocêntrica do autor), não deixa de apostar na atualidade do texto: o que nele há de humanista e cosmopolita ainda o torna legível e provocador, efetivamente, capaz de ser um recurso para o debate sobre a globalização e conflito intercultural.
} 
da história de seu tempo, com os quais é possível estabelecer um diálogo. De um lado, temos a postura típica do "Sturm und Drang" (“Tempestade e Ímpeto") de um autor como Johann Gottfried Herder, sobretudo, em seu texto Também uma filosofia da história para a formação da humanidade (1774) e, de outro, a concepção claramente iluminista de Immanuel Kant, classicamente manifesta em Ideia de uma história universal de um ponto de vista cosmopolita, obra escrita dez anos após o panfleto de Herder.

Não é necessário conhecer profundamente o breve livro de Herder para saber que, ao menos em um primeiro momento, ele está em franca oposição às palavras de Schiller. A seguinte passagem é ilustrativa:

\begin{abstract}
Vulgarmente o filósofo transforma-se tanto mais em animal quanto mais está convencido de que é Deus. E o mesmo acontece com quem está convencido de que é possível fazer cálculos sobre o aperfeiçoamento do mundo. Com aquele que se convence de que tudo progride belamente segundo uma linha reta e de que cada indivíduo e cada geração se limitam a enfileirar numa bela progressão da qual só ele conhece a fórmula de virtudes e felicidade que regula o aperfeiçoamento geral à imagem de seu próprio ideal. Tudo viria afinal a desembocar nele, último e mais elevado elo da cadeia, com o qual tudo se termina (HERDER, 1995, p. 95).
\end{abstract}

O contraste é claro, pois, em Schiller, a linearidade é o fio que tece a narrativa da história universal de uma humanidade cada vez mais aperfeiçoada. Em contrapartida, como percebeu bem Peter-Hans Reill (2006), ambos empregam, largamente, o recurso analógico de representação e explicação do processo histórico. Dou razão a Johannes Rohbeck (2006, p. 83), ao pontuar que Schiller se mostra sensível para um tema atualíssimo na teoria da história, a saber, a "diacronia do sincrônico", que ele percebe não somente em escala mundial, mas também dentro da Europa. Afinal, Herder também perceberia algo semelhante, ainda que em texto posterior ao seu opúsculo sobre a filosofia da história. Portanto, a despeito das diferenças, há traços em comum, ainda que Reill e Rohbeck minimizem uma distinção fundamental: o lado providencialista e nacionalista de Herder e a concepção secularizada e cosmopolita de Schiller.

E da mesma forma que Herder e Schiller não são absolutamente distintos, Schiller e Kant - ao menos o Kant da Idéia de uma história universal - não são absolutamente idênticos. Se, de fato, há um plano na história universal, de outro modo, Schiller enfatiza a dimensão trágica e culpada da consciência desse plano. Em primeiro lugar - algo que Kant, até onde pude perceber, jamais afirma -, ele diz que inúmeras ações humanas não podem mais ser conhecidas; em segundo lugar, esse conhecimento 
possível se dá na consciência quase como um fardo. É necessário reconhecer cada passo do caminho percorrido, e pôr-se quase em dívida com ele. A sucessão de eventos resultou em nós - mas não há razão para orgulho arrogante, mas, sim, exigência de reconhecimento. O passado não deve ser julgado (como poderia querer o iluminista mais dogmático) nem recuperado (como poderia pretender o historicista mais nostálgico), mas é uma forma de, para lembrar as palavras de um crítico musical ${ }^{5}$, intensificar o presente, vendo-lhe suas profundas camadas temporais. Essa consciência da continuidade, portanto, é mais do que uma estratégia narrativa. É a própria definição da Bildung, homem culto, do gebildeter Mensch, como aquele capaz de construir em si a imagem da continuidade, para usar a definição imbatível de Jacob Burckhardt (2010, p.178).

Esse ideal da Bildung aparecerá em outro momento, talvez no trecho mais provocador da conferência, a saber, quando Schiller contrapõe o pragmatismo do estudioso ganha-pão com a mente filosófica. Aqui, precisamos nos separar decididamente do autor, pois em uma época em que as universidades são inevitavelmente instituições de massa e devem ser inclusivas, é cruel condenar um estudante por buscar, no estudo superior, um meio de ganhar a vida. O pensamento de Schiller só se torna minimamente aproveitável ao lembrarmos que ele critica a instrumentalização do conhecimento como meio, sobretudo, para aquisição de prêmios, fama ou qualquer outra chancela externa. E aí, suspeito que a universidade não somente não tenha se libertado desse problema, como não dá muitos sinais de tentar querer sair de tal condição.

Assim, se, por um lado, devemos ser capazes de declarar, com alguma tranquilidade, o caráter obsoleto do tex to de Schiller pelo que contém de potencialmente eurocêntrico e ingenuamente teleológico, por outro, o que ele transmite sobre o ideal do homem culto também pode estar igualmente ultrapassado, mas isso não necessariamente depõe a nosso favor. O impressionante, porém, é que, até neste aspecto, Schiller se mantém irredutível, ambivalente, trágico.

\footnotetext{
5 "O melhor tipo de interpretação clássica não é um recuo para o passado, mas uma intensificação do presente" (ROSS, 2011, p. 35).
} 


\section{REFERÊNCIAS}

ALT, Peter-André. Friedrich Schiller. Munique: Beck, 2004.

BARBOSA, Ricardo. Schiller \& a cultura estética. Rio de Janeiro: Jorge Zahar Ed., 2004.

BURCKHARDT, Jacob. Kritische Gesamtausgabe Bd. 20: Grieschiche Culturgeschichte, Band II. Basel: Schwabe; München: C.H. Beck, 2005.

BURCKHARDT, Jacob. História da Cultura Grega: Introdução (1872). In: MARTINS, Estevão de Rezende (Org.). A História pensada: teoria e método na historiografia europeia do século XIX. São Paulo: Contexto, 2010.

HERDER, Johann Gottfried. Também uma filosofia da história para a formação da humanidade. Lisboa: Antígona, 1995.

HOFMANN, Michael. Schiller: Epoche - Werke - Wirkung. Munique: Beck, 2003.

HOFMANN, Michael; RÜSEN, Jörn (Org.). Schiller und die Geschichte. Munique: Wilhelm Fink, 2006.

MANN, Thomas. Hora difícil. In: MANN, Thomas. Os Famintos e outras histórias. Rio de Janeiro: Nova Fronteira, 2000.

REILL, Peter-Hans. Schiller, Herder and History. In: HOFMANN, Michael; RÜSEN, Jörn. Schiller und die Geschichte. Munique: Wilhelm Fink, 2006.

ROHBECK, Johannes. Universalgeschichte und Globalisierung: Zur Aktualität von Schillers Geschichtsphilosophie. In: HOFMANN, Michael \& RÜSEN, Jörn. Schiller und die Geschichte. Munique: Wilhelm Fink, 2006.

ROSS, Alex. Escuta só: do clássico ao pop. São Paulo: Companhia das Letras, 2011.

RÜSEN, Jörn. Der Funken der Utopie im Feuer der Geschichte: Schillers Beitrag zu unserer Deutung der Vergangenheit. In: RÜSEN, Jörn; HOFMANN, Michael. Schiller und die Geschichte. Munique: Wilhelm Fink, 2006.

SCHILLER, Friedrich. Guilherme Tell. Tradução de Silvio Meira. Rio de Janeiro: Serviço Nacional de Teatro, 1974.

SCHILLER, Friedrich. Maria Stuart. Tradução de Manuel Bandeira. São Paulo: Abril Cultural, 1977.

SCHILLER, Friedrich. A Educação estética do homem. Tradução de Roberto Schwarz e Márcio Suzuki. São Paulo: Iluminuras, 1990.

SCHILLER, Friedrich. Poesia ingênua e sentimental. Tradução de Márcio Suzuki. São Paulo: Iluminuras, 1991. 
SCHILLER, Friedrich. Os Bandoleiros. Tradução de Marcelo Backes. Porto Alegre: L\&PM, 2001.

SCHILLER, Friedrich. Kallias ou sobre a Beleza: A correspondência entre Schiller e Körner. Janeiro - fevereiro de 1793. Tradução de Ricardo Barbosa. Rio de Janeiro: Jorge Zahar Ed., 2002.

SCHILLER, Friedrich. A noiva de Messina. Tradução de Gonçalves Dias. Márcio Suzuki; Samuel Titan Jr. (Org.). São Paulo: Cosac \& Naify, 2004.

SCHILLER, Friedrich. Os Deuses da Grécia. In: ASSIS, Machado de. Toda poesia de Machado de Assis. Claudio Murilo Leal (Org.). Rio de Janeiro: Record, 2008.

SCHILLER, Friedrich. Cultura estética e liberdade. Organização e tradução de Ricardo Barbosa. São Paulo: Hedra, 2009.

SCHILLER, Friedrich. Do sublime ao trágico. Pedro Süssekind (Org.). Tradução e ensaios de Pedro Süssekind e Vladimir Vieira. Belo Horizonte: Autêntica, 2011.

SCHILLER, Friedrich; GOETHE, Johann Wolfgang. Correspondência. Tradução de Claudia Cavalcanti. São Paulo: Hedra, 2010.

SÜSSEKIND, Pedro. Schiller e os gregos. Kriterion, Belo Horizonte, n.112, dez. 2005, p.243-259.

SÜSSMANN, Johannes. Denken in Darstellungen - Schiller und die Geschichte. In: HOFMANN, Michael; RÜSEN. Jörn. Schiller und die Geschichte. Munique: Wilhelm Fink, 2006.

VIEIRA, Vladimir de Menezes. Entre a Razão e a Sensibilidade: a estética póskantiana e o problema da cisão entre sensível e supra-sensível. 2009. Tese (doutorado em Filosofia) - Universidade Federal do Rio de Janeiro, Programa de Pós-Gradução em Filosofia, Rio de Janeiro, 2009. 